Research Article

\title{
A Voltammetric Properties of Biopolymer Nano- Composites Based Polybutylene Succinate/Epoxidized Palm Oil
}

\author{
Manar Ghyath Abd-Almutalib Al-Mosawy ${ }^{1}$, Emad Abbas Jaffar Al-Mulla ${ }^{2}$, Muhammed Mizher \\ Radhi $^{3}$ \\ ${ }^{1}$ Department of Chemistry, Faculty of Science, University of Kufa, P.O. Box 21, An-Najaf 54001, Iraq. \\ ${ }^{2}$ College of Health and Medical Techniques, Al-Furat Al-Awsat Technical University, 54003 Al-Kufa, Iraq. \\ ${ }^{3}$ Radiologic Technical Department, Health and Medical Technology College-Baghdad, Middle Technical University, Baghdad, Iraq. \\ Corresponding author. E-mail: almullaemad@gmail.com
}

Received: Mar. 16, 2018; Accepted: Apr. 18, 2018; Published: Jul. 23, 2018.

Citation: Manar Ghyath Abd-Almutalib Al-Mosawy, Emad Abbas Jaffar Al-Mulla, and Muhammed Mizher Radhi, A Voltammetric Properties of Biopolymer Nano-composites Based Polybutylene Succinate/Epoxidized Palm Oil. Nano Biomed. Eng., 2018, 10(3): 217-223.

DOI: 10.5101/nbe.v10i3.p217-223.

\begin{abstract}
A glassy carbon electrode (GCE) was modified with a polybutylene succinate/epoxidized palm oil (PBS/EPO) clay nanocomposites; by using solution evaporation method, a new modified electrode PBS/EPO-clay nanocomposite was produced. The redox process of $\mathrm{K}_{4}\left[\mathrm{Fe}(\mathrm{CN})_{6}\right]$ during cyclic voltammetry was studied using the PBS/EPO-clay nanocomposites. It was found that the peak separation $\left(\Delta\right.$ Epa-c) between the redox peaks of $\mathrm{Fe}(\mathrm{II}) / \mathrm{Fe}(\mathrm{III})$ in an aqueous solution of $0.1 \mathrm{M} \mathrm{KClO}_{4}$ and the current ratio of redox current peaks, $(\mathrm{Ipa} / \mathrm{Ipc})$ was $\approx 1$ for the modified working electrode with PBS/EPO-clay nanocomposites, indicating good reversibility with weak conductivity of the modified electrode. The physical properties of the modified electrode PBS/EPO-clay nanocomposites included good hardness, high adhesion to the glassy carbon surfaces of electrode collectors, solubility and good stability of the PBS/EPO-clay nanocomposites at different $\mathrm{pH}$ media. Also, the sensitivity of the electrochemical analysis by cyclic voltammetric method was significantly dependent on the $\mathrm{pH}$ and the scan rate (SR). It was found that the couple of redox current peaks of $\mathrm{K}_{4}\left[\mathrm{Fe}(\mathrm{CN})_{6}\right]$ in $\mathrm{KClO}_{4}$ solution were a reversible process: $\mathrm{Fe}(\mathrm{III}) / \mathrm{Fe}(\mathrm{II})$.
\end{abstract}

Keywords: Cyclic voltammetry; PBS/EPO-clay nanocomposites; $\mathrm{KClO}_{4} ; \mathrm{Fe}(\mathrm{II}) / \mathrm{Fe}(\mathrm{III}) ; \mathrm{K}_{4}\left[\mathrm{Fe}(\mathrm{CN})_{6}\right]$

\section{Introduction}

In many previous studies in electrochemistry of cyclic voltammetric method, it was found that the conductive grafted polymer was improved by modifying the solid bar electrodes with these grafted polymers [1-6]. One of the most promising candidates for biodegradable synthetic polymers is polybutylene succinate (PBS) $[7,8]$. Accordingly, many efforts have been made by materials scientists and engineers to discover, develop and modify biodegradable polymers derived from renewable resources [9].

The PBS is one of the biodegradable thermoplastic polyesters which can be prepared from butane diol and succinic acid produced by fermentation process $[10$, 11]. In addition to its applications in textile industry and medical fields, PBS is a promising candidate to produce disposable packaging. However, low 
molecular weight, low stiffness and high cost restrict its applications [12]. Many studies have been conducted to enhance the properties by blending biodegradable polymers with other polymers or using low molecular weight plasticizers [13-19]. The morphologies and phase behaviors of polylactic acid/PBS blend were investigated by Park et al. [20], while the structures and properties of this blend were studied by Yokohara et al. [21]. Jin et al. reported that physical, thermal properties and biodegradation of PBS were improved by modifying it with peroxide [22]. The epoxidized palm oil (EPO) was used to improve properties and biodegradation of PBS.

The EPO was produced from esters of glycerol in palm oil containing different saturated and unsaturated fatty acids. It offers many advantages in chemical industries, because it is derived from renewable, biodegradable and abundant raw materials $[15,23,24]$.

The incorporation of organoclays in the polymer to produce a nanocomposite is another means to modify the property balance of a material. The improvements in thermal stability, physical and mechanical properties can be achieved by addition of $0.5-5 \%$ weight of organoclays in comparison to the neat polymer [25, 26]. The modification of natural clay (montmorillonite) may be carried out via exchanging the original interlayer cations by organic cations where they are transformed from organophobic to organophilic materials and significantly increase the basal spacing of the clay layers [27]. It is generally accepted that the extent of swelling depends on the length of the alkyl chain and the cation-exchange capacity of the clay [28]. Organoclays are mainly obtained by exchanging cations in the clay minerals which contain hydrated $\mathrm{Na}^{+}$ions with alkylammonium [29].

Processing and properties of PBS/EPO montmorillonite nanocomposites were investigated and characterized by using $\mathrm{X}$-ray diffraction (XRD), transmission electron microscopy (TEM). Plasticized PBS-based nanocomposites were prepared and characterized with epoxidized palm oil and montmorillonite. It was reported that the organomodified montmorillonite-based composites showed the possible competition between the polymer matrix and the plasticizer for the intercalation between the aluminosilicate layers.

In this study, hexadecane-1-amine (HAD) was used to modify the compatibility of montmorillonite clay with polymer. The present study used plasticized PBS- based nanocomposites, EPO and montmorillonite modified by HDA. The modified working electrode with PBS/EPO-clay nanocomposite and its conductivity were also investigated in this study.

\section{Experimental \\ Instruments, materials and electro-analytical analysis methods}

Instruments: EZstat series (potentiostat/glvanostat), NuVant Systems Inc., USA. The electrochemical workstations of Bioanalytical system with potetiostate driven by electroanalytical measuring softwares were connected to a personal computer to perform cyclic voltammetry $(\mathrm{CV})$.

Materials: $\mathrm{Ag} / \mathrm{AgCl}(3 \mathrm{M} \mathrm{NaCl})$ and a platinum wire (1 mm diameter) were used as a reference and a counter electrode, respectively. The modified glassy carbon working electrode (GCE) was used in this study after cleaning with alumina grand.

Procedure: Cyclic voltammetric cell was used in this technique by adding $10 \mathrm{~mL}$ of electrolyte in the quartz cell, and immersing 3 electrodes in the electrolyte medium with the PBS/EPO-clay nanocomposites as working electrode, $\mathrm{Ag} / \mathrm{AgCl}$ reference electrode and counter electrode. Then, the 3 electrodes were connected with potentiostat to obtain the results of cyclic voltammogram using personal computer.

\section{Reagents}

Sodium montmorillonite and HDA were obtained from Sigma Aldrich, Germany. EPO was provided by Advanced Oleo Chemical Technology Division (AOTD), Malaysia. PBS and chloroform were purchased through local suppliers from Nagoya, Japan and Merck, Germany, respectively. Hydrochloric acid was from J.T. Baker, USA. All the reagents were analytical reagents of electrochemical grade purity. All solutions were prepared by using deionize water. Unless otherwise specified, the supporting electrolyte was $1 \mathrm{M} \mathrm{KClO}_{4}$ in an aqueous medium at room temperature.

\section{Preparation of organoclay}

Organoclay was prepared with a cationic exchange process, where $\mathrm{Na}^{+}$in the montmorillonite was exchanged with alkylammonium ion from HDA, as reported in our previous paper [30]. In an aqueous solution. $4 \mathrm{~g}$ of sodium montmorillonite (Na-MMT) was stirred vigorously in $600 \mathrm{~mL}$ hot distilled water for $1 \mathrm{~h}$ to form a clay suspension. Subsequently, a 
designated amount of HDA compounds were dissolved in $400 \mathrm{~mL}$ hot water, and the desired amount of concentrated hydrochloric acid $(\mathrm{HCl})$ was added into the clay suspension of HDA compounds. After being stirred vigorously for $1 \mathrm{~h}$ at $80{ }^{\circ} \mathrm{C}$, the organoclay suspension was filtered and washed with distilled water until no chloride was detected using a $1 \mathrm{M}$ silver nitrate solution, and then dried at $60{ }^{\circ} \mathrm{C}$ for $72 \mathrm{~h}$. Structure of HDA is shown in Scheme 1.

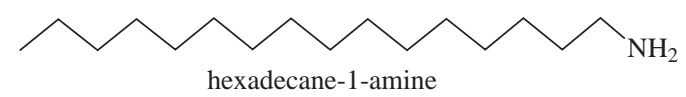

Scheme 1 Structures of hexadecane-1-amine (HAD).

\section{Preparation of PBS/EPO-clay nanocomposites}

The required amount of PBS and EPO was dissolved in $50 \mathrm{~mL}$ chloroform separately. The EPO solution was then transferred into the PBS solution with a dropper and with continuous stirring. After all the EPO solution was transferred into the PBS solution, the resultant mixture was then stirred for $1 \mathrm{~h}$. The required modified clay HDA-MMT was then added into the dissolved PBS/ EPO in a small portion. The mixture was then refluxed for $1 \mathrm{~h}$ and then ultrasonically stirred using the ultrasonic cathode for $10 \mathrm{~min}$ to make sure that the clay was fully dispersed in the PBS/EPO solution. The nanocomposite was then poured into a Petri dish and left to dry. The amount of PBS/EPO and the modified clay used in this study are listed in Table 1.

\section{Results and Discussion Effect of 82 PBS 8 EPO/HDA-MMT modified GCE on the redox reaction of $\mathrm{K}_{4}\left[\mathrm{Fe}(\mathrm{CN})_{6}\right]$ during $\mathrm{CV}$}

The PBS/EPO blend clay nanocomposites, at the weight ratio of $80: 20 \%(\mathrm{mg}) \mathrm{EPO} / \mathrm{HDA}-\mathrm{MMT}$, were chosen because they had redox properties. Potassium ferrous cyanide $\mathrm{K}_{4}\left[\mathrm{Fe}(\mathrm{CN})_{6}\right]$ is commonly used as a reference standard for the purpose of calibrating a voltammetric system in aqueous solutions. The calibration process of an electroanalytical work station using GCE and PBS/EPO/HDA-MMT modified GCE was depending on the supporting electrolyte as shown in Table 3 in the presence of PBS/EPO/HDA-MMT. The redox potential with $\mathrm{Epc}=264 \mathrm{mV}$ and $\mathrm{Epa}=$ $68.7 \mathrm{mV}$ was observed for the electrolyte, indicating the reversible reaction of the $\mathrm{Fe}(\mathrm{III}) / \mathrm{Fe}$ (II) coupled in the $\mathrm{KClO}_{4}$ solution and agreed well with the accepted values.

Also, the ratio value of redox current was close to $1(\mathrm{Ipa} / \mathrm{Ipc}=1.8)$ for $\mathrm{PBS} / \mathrm{EPO} / \mathrm{HDA}-\mathrm{MMT}$, which suggested that the reaction of $\mathrm{Fe}(\mathrm{III}) / \mathrm{Fe}(\mathrm{II})$ was a reversible process when using the $\mathrm{PBS} / \mathrm{EPO} / \mathrm{HDA}-$ MMT as shown in Fig. 1.

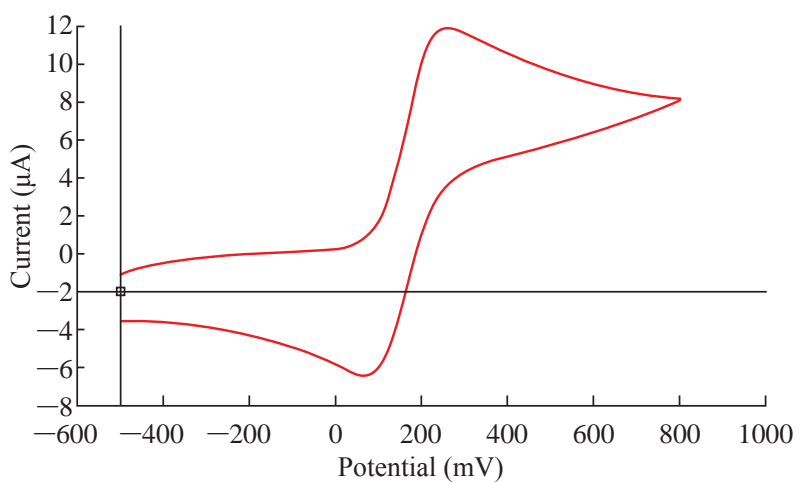

Fig. 1 Cyclic voltammogram of $1 \mathrm{mM} \mathrm{K}_{4}\left[\mathrm{Fe}(\mathrm{CN})_{6}\right]$ in $0.1 \mathrm{M}$ $\mathrm{KClO}_{4}: \mathrm{PBS} / \mathrm{EPO} / \mathrm{HDA}-\mathrm{MMT} / \mathrm{GCE}$ using scan rate of $100 \mathrm{mV} / \mathrm{s}$ and $\mathrm{Ag} / \mathrm{AgCl}$ as a reference electrode.

\section{Effect of varying the supporting electrolyte}

The different supporting electrolytes exerted a slight influence on the oxidation peak potential of $\mathrm{Fe}$ (III) as expected, especially in non-complexing solutions (Table 2 and 3). In general, the redox peaks of Fe(III) appeared to have a similar pattern of peak formation in different types of the supporting electrolyte. However, regarding the redox current, especially the oxidation peak current of the $\mathrm{Fe}(\mathrm{II}) / \mathrm{Fe}$ (III) couple, the greatest

Table 1 Amount of PBS/EPO and the modified clay

\begin{tabular}{cccc}
\hline Sample & Weight of PBS $(\mathrm{g})$ & Weight of EPO $(\mathrm{g})$ & Weight of organoclay $(\mathrm{g})$ \\
\hline 1 & 0.9 & 0.1 & 0.00 \\
2 & 0.86 & 0.09 & 0.05 \\
3 & 0.82 & 0.08 & 0.1 \\
4 & 0.78 & 0.07 & 0.15 \\
5 & 0.74 & 0.06 & 0.2 \\
6 & 0.5 & 0.25 & 0.25 \\
\hline
\end{tabular}

Note: $\mathrm{PBS}=$ polybutylene succinate; $\mathrm{EPO}=$ epoxiduzed palm oil. 
Table 2 Cyclic voltammetry of $1 \mathrm{mM}$ potassium ferrocyanide in different electrolytes, $0.1 \mathrm{M}$ of $\mathrm{KClO}_{4}, \mathrm{KNO}_{3}$ and $\mathrm{KCl}$, at scan rate of $100 \mathrm{mV} / \mathrm{s}$ for the PBS/EPO/HDA-MMT in anode

\begin{tabular}{cccc}
\hline Modified electrolyte & Electrolyte & Epa $(\mathrm{mV})$ & $\mathrm{Ipa}(\mu \mathrm{A})$ \\
\hline $\mathrm{H}_{2} / \mathrm{GCE}$ & $\mathrm{KClO}_{4}$ & 264 & 12.0 \\
$\mathrm{H}_{2} / \mathrm{GCE}$ & $\mathrm{KNO}_{3}$ & 263 & 1.93 \\
$\mathrm{H}_{3} / \mathrm{GCE}$ & $\mathrm{KCl}$ & 227.8 & 6.12 \\
\hline
\end{tabular}

Note: GCE = glassy carbon electrode; Epa = peak anodic potential; Ipa = anodic peak current.

Table 3 Cyclic voltammetry of $1 \mathrm{mM}$ potassium ferrocyanide in different electrolytes, $0.1 \mathrm{M}$ of $\mathrm{KClO}_{4}, \mathrm{KNO}_{3}$ and $\mathrm{KCl}$, at scan rate of $100 \mathrm{mV} / \mathrm{s}$ for the PBS/EPO/HDA-MMT in cathode

\begin{tabular}{cccc}
\hline Modified electrolyte & Electrolyte & Epc $(\mathrm{mV})$ & $\mathrm{Ipc}(\mu \mathrm{A})$ \\
\hline $\mathrm{H}_{2} / \mathrm{GCE}$ & $\mathrm{KClO}_{4}$ & 68.7 & 6.4 \\
$\mathrm{H}_{2} / \mathrm{GCE}$ & $\mathrm{KNO}_{3}$ & 74.0 & 0.815 \\
$\mathrm{H}_{3} / \mathrm{GCE}$ & $\mathrm{KCl}$ & 172.4 & 3.78 \\
\hline
\end{tabular}

Note: GCE = glassy carbon electrode; Epa = peak anodic potential; Ipa = anodic peak current.

effect was obtained when $\mathrm{KClO}_{4}$ was used as the electrolyte. In general, the degree of oxidation current enhancement in varying electrolyte varied in the following order:

$\mathrm{KClO}_{4}>\mathrm{KNO}_{3}>\mathrm{KCl}$.

Furthermore, the reduction current enhancement was in the following order:

$\mathrm{KCl}>\mathrm{KNO}_{3}>\mathrm{KClO}_{4}$.

\section{Effect of varying the scan rate}

The effect of varying the scan rate on the cyclic voltammograms of $\mathrm{Fe}(\mathrm{III}) / \mathrm{Fe}$ couple using $\mathrm{PBS} / \mathrm{EPO} /$ HDA-MMT/GCE as the working electrode in $0.1 \mathrm{M}$ $\mathrm{KClO}_{4}$ supporting electrolyte was studied over 0.01$0.1 \mathrm{mV} / \mathrm{s}$ in the potential. Redox current peaks of the $\mathrm{Fe}(\mathrm{II}) / \mathrm{Fe}$ (III) couple were observed to increase with the scan rate due to heterogeneous kinetics. Based on a plot of Ipa log versus scan-rate log for the oxidation current of the first cycle, a straight line was obtained (Fig. 2) fulfilling the equation $y=0.0192 x+1.1484$,

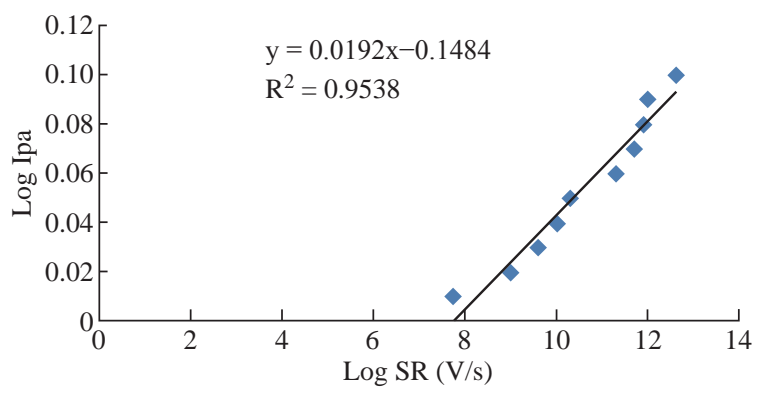

Fig. 2 Plot of Ipa $\log$ of $1 \mathrm{mM} \mathrm{K}_{4}\left[\mathrm{Fe}(\mathrm{CN})_{6}\right]$ in $1 \mathrm{M} \mathrm{KClO}_{4}$ against scan-rate log using $\mathrm{PBS} / \mathrm{EPO} / \mathrm{HDA}-\mathrm{MMT} / \mathrm{GCE}$ at different scan rates from $0.1-3 \mathrm{mV} / \mathrm{s}$. with good sensitivity as $\mathrm{R}^{2}=0.9538$ and a slope of 0.0192 .

\section{Reliability and stability of PBS/EPO/had-MMTI GCE}

The potential cycling of the redox current peaks of the modified working electrode of PBS/EPO/HDAMMT/GCE in $0.1 \mathrm{mM} \mathrm{K}_{4}\left[\mathrm{Fe}(\mathrm{CN})_{6}\right]$ with $0.1 \mathrm{M} \mathrm{KClO}_{4}$ was carried out during cyclic voltammetry. Continuous potential cycling did not seem to affect the redox current peak of the new modified working electrode, since the faradic activity appeared reliable even after different times, and the relative standard deviation (RSD) was $\pm 1.06 \%$ as shown in Table 4 . Table 5 shows the reliability of PBS/EPO/HDA-MMT/GCE as working electrode at scan rate $=100 \mathrm{mV} / \mathrm{s}$ for anodic peak of $0.1 \mathrm{mM} \mathrm{K}_{4}\left[\mathrm{Fe}(\mathrm{CN})_{6}\right]$ in $0.1 \mathrm{M} \mathrm{KCl}$ and $\mathrm{RSD}=$ $\pm 0.50 \%$.

Table 4 Reliability of PBS/EPO/HDA-MMT/GCE as working electrode at scan rate $=100 \mathrm{mV} / \mathrm{s}$ for cathodic peak of $0.1 \mathrm{mM}$ $\mathrm{K}_{4}\left[\mathrm{Fe}(\mathrm{CN})_{6}\right]$ in $0.1 \mathrm{M} \mathrm{KClO}_{4}$

\begin{tabular}{cccc}
\hline No. & Ipc $(\mu \mathrm{A})$ & Mean & RSD \\
\hline 1 & 5.47 & & \\
2 & 5.49 & & \\
3 & 5.51 & & \\
4 & 5.53 & & \\
5 & 5.55 & & \\
6 & 5.57 & 5.56 & \\
7 & 5.59 & & \\
8 & 5.61 & & \\
9 & 5.63 & & \\
10 & 5.65 & & \\
\hline
\end{tabular}

Note: Ipc $=$ cathodic peak current; RSD = relative standard deviation. 
Table 5 Reliability of PBS/EPO/HDA-MMT/GCE as working electrode at scan rate $=100 \mathrm{mV} / \mathrm{s}$ for anodic peak of $0.1 \mathrm{mM}$ $\mathrm{K}_{4}\left[\mathrm{Fe}(\mathrm{CN})_{6}\right]$ in $0.1 \mathrm{M} \mathrm{KClO}_{4}$

\begin{tabular}{cccc}
\hline No. & Ipa (uA) & Mean & RSD \\
\hline 1 & 12 & & \\
2 & 12.02 & & \\
3 & 12.04 & & \\
4 & 12.06 & & \\
5 & 12.08 & & \\
6 & 12.10 & 12.09 & \\
7 & 12.12 & & \\
8 & 12.14 & & \\
9 & 12.16 & & \\
10 & 12.18 & & \\
\hline
\end{tabular}

Note: Ipa $=$ anodic peak current; $\mathrm{RSD}=$ relative standard deviation.

Fig. 3 shows the stability of PBS/EPO/HDA-MMT/ GCE on the surface of GCE by about 10-time cyclic voltammetry. The figure shows overlapping of the 10time cyclic voltammogram of $0.1 \mathrm{mM} \mathrm{K}_{4}\left[\mathrm{Fe}(\mathrm{CN})_{6}\right]$ in $0.1 \mathrm{M} \mathrm{KClO}_{4}$.

\section{Effect of varying the $\mathrm{K}_{4}\left[\mathrm{Fe}(\mathrm{CN})_{6}\right]$ concentration}

Fig. 4 shows the calibration curve of different concentrations from $0.01-0.07 \mathrm{mM}$ of $\mathrm{K}_{4}\left[\mathrm{Fe}(\mathrm{CN})_{6}\right]$ in $0.1 \mathrm{M} \mathrm{KClO}_{4}$, which was described by the equation $\mathrm{y}=$ $105.29 x-6.0271$, with $R^{2}=0.7899$. The linearity of the

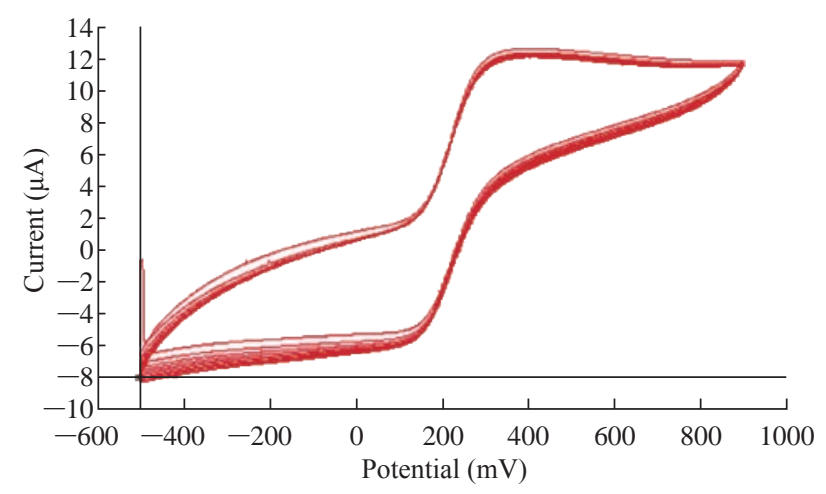

Fig. 3 Cyclic voltammogram of 10 times of $\mathrm{K}_{4}\left[\mathrm{Fe}(\mathrm{CN})_{6}\right]$ in 0.1 $\mathrm{M} \mathrm{KClO}_{4}$ using PBS/EPO/HDA-MMT/GCE.

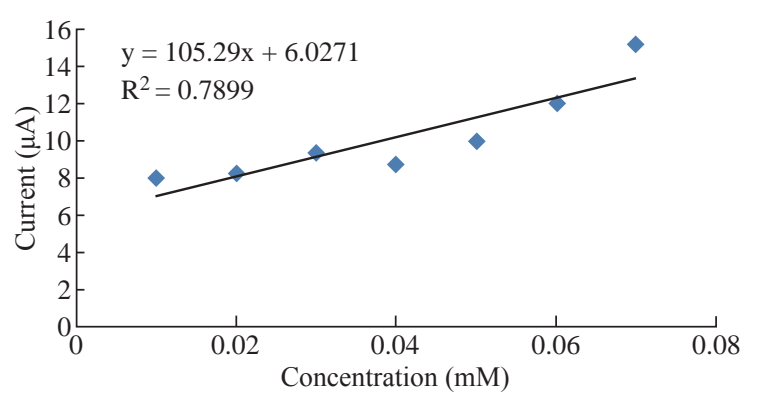

Fig. 4 Plot of anodic current versus different concentrations of $\mathrm{K}_{4}\left[\mathrm{Fe}(\mathrm{CN})_{6}\right]$ using PBS/EPO/HDA-MMT/GCE. plot was observed for a $\mathrm{K}_{4}\left[\mathrm{Fe}(\mathrm{CN})_{6}\right]$ concentration of up to $0.01 \mathrm{mM}$ with an impressive current sensitivity of close to $105.29 \mu \mathrm{A} / \mathrm{mM}$.

Fig. 5 shows the calibration curve of different concentrations from $0.01-0.07 \mathrm{mM}$ of $\mathrm{K}_{4}\left[\mathrm{Fe}(\mathrm{CN})_{6}\right]$ in $0.1 \mathrm{M} \mathrm{KClO}_{4}$, which was described by the equation $\mathrm{y}$ $=66.893 \mathrm{x}-5.7129$, with $\mathrm{R}^{2}=0.86$. The linearity of the plot was observed for a $\mathrm{K}_{4}\left[\mathrm{Fe}(\mathrm{CN})_{6}\right]$ concentration of up to $0.01 \mathrm{mM}$ with an impressive current sensitivity of close to $66.893 \mu \mathrm{A} / \mathrm{mM}$.

\section{Voltammetric characterization of 80 PBS 20 EPO/HDA-MMT-GCE modified in different $\mathrm{pH}$}

Fig. 6 shows the effects of different $\mathrm{pH}$ for $1 \mathrm{M}$ $\mathrm{K}_{4}\left[\mathrm{Fe}(\mathrm{CN})_{6}\right]$ in $0.1 \mathrm{KClO}_{4}$ solution using $\mathrm{HCl}$ or $\mathrm{NaOH}$ solution on $\mathrm{PBS} / \mathrm{EPO} / \mathrm{H}_{2}-\mathrm{MMT}$. It was found that the oxidation current peaks of $\mathrm{K}_{4}\left[\mathrm{Fe}(\mathrm{CN})_{6}\right]$ decreased with the solution $\mathrm{pH}$ in high acidic values. Fig. 6 illustrate the plot of anodic current peaks of $\mathrm{Fe}(\mathrm{II}) / \mathrm{Fe}$ (III) against $\mathrm{pH}$. Also, the enhancement of oxidation current peaks increased at a high alkaline $\mathrm{pH}$ of 6 , as shown in Fig. 6 which illustrates the plot of anodic current peaks of $\mathrm{Fe}(\mathrm{II}) / \mathrm{Fe}(\mathrm{III})$ against $\mathrm{pH}$. There was a decrease in the current at $\mathrm{pH}=8.5$ in the oxidation process, which meant that the current dropped with alkaline solution, and increased with acidic medium and alkaline solutions above 8.5.

Fig. 7 shows the effect of different $\mathrm{pH}$ for $1 \mathrm{M}$ $\mathrm{K}_{4}\left[\mathrm{Fe}(\mathrm{CN})_{6}\right]$ in $0.1 \mathrm{KClO}_{4}$ solution using $\mathrm{HCl}$ or $\mathrm{NaOH}$

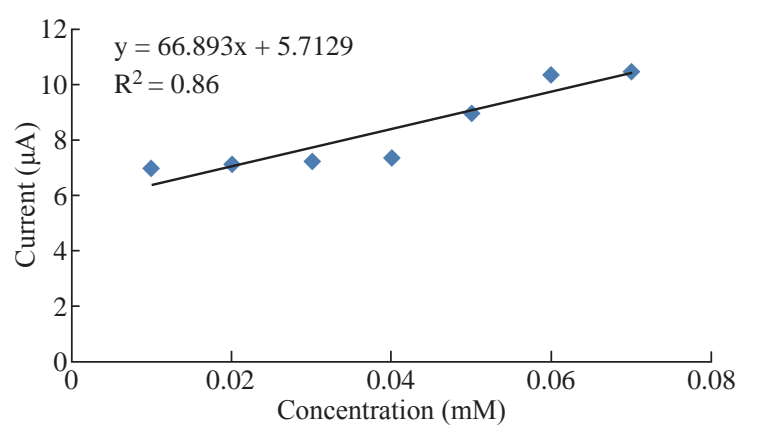

Fig. 5 Plot of cathodic current versus different concentrations of $\mathrm{K}_{4}\left[\mathrm{Fe}(\mathrm{CN})_{6}\right]$ using PBS/EPO/HDA-MMT/GCE.

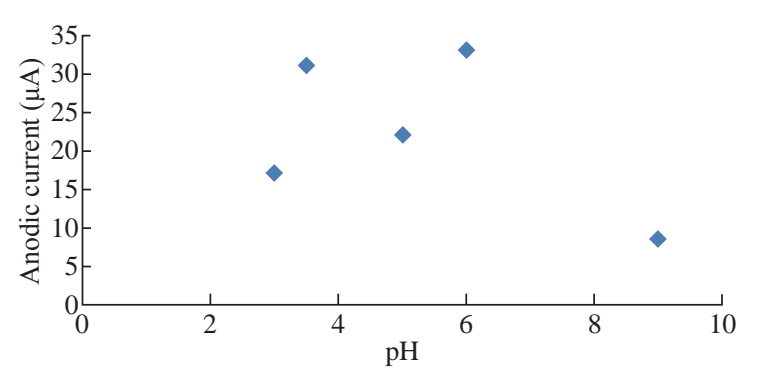

Fig. 6 Plot oxidation current peak of $\mathrm{Fe}(\mathrm{II}) / \mathrm{Fe}(\mathrm{III})$ against $\mathrm{pH}$. 
solution on $\mathrm{PBS} / \mathrm{EPO} / \mathrm{H}_{2}-\mathrm{MMT}$. It was found that the redox current peaks of $\mathrm{K}_{4}\left[\mathrm{Fe}(\mathrm{CN})_{6}\right]$ increased with the solution $\mathrm{pH}$ in high acidic values. Fig. 7 illustrate the plot of cathodic current peaks of $\mathrm{Fe}(\mathrm{II}) / \mathrm{Fe}$ (III) against $\mathrm{pH}$. Also, the enhancement of redox current peaks increased at a high alkaline $\mathrm{pH}$ of 2 , as shown in Fig. 7 which illustrate the plot of anodic current peaks of $\mathrm{Fe}(\mathrm{II}) / \mathrm{Fe}$ (III) against $\mathrm{pH}$. There was a decrease in the current at $\mathrm{pH}=9$ in the oxidation process, which meant that the current dropped with alkaline solution, and increased with the decreasing $\mathrm{pH}$ of acidic medium and alkaline solutions above 9 .

\section{Transmission electron microscopy (TEM)}

TEM micrographs of the PBS/EPO composites showed that the original Na-MMT stack morphology was fully preserved with PBS/EPO due to the incompatible nature of both constituents [30] (Fig. 8). The dark lines represented the thickness of the individual clay layers or agglomerates (tactoids; stacks). The organoclay did not show its original layered structure. The related structure could be referred to as intercalated lamellae, tactoids composed of a variable number of lamellae and aggregates of tactoids. The TEM micrograph shows a higher degree

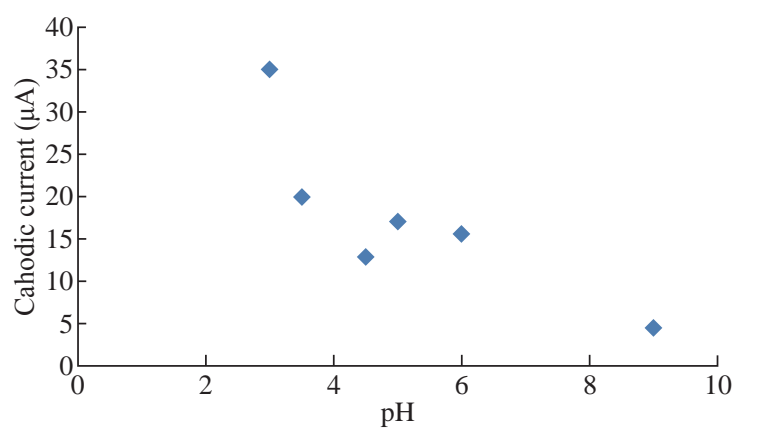

Fig. 7 Plot reduction current peak of $\mathrm{Fe}(\mathrm{II}) / \mathrm{Fe}(\mathrm{III})$ against $\mathrm{pH}$.

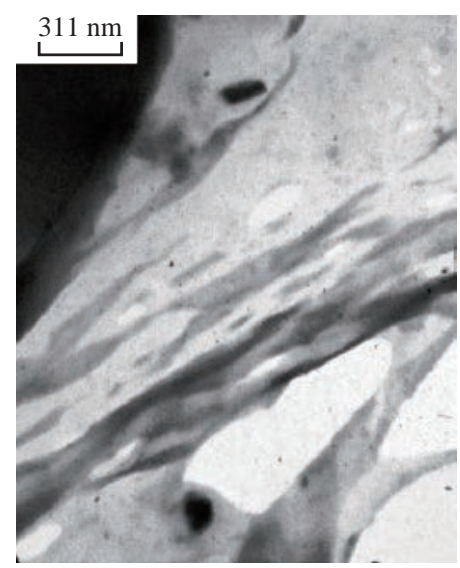

Fig. 8 Transmission electron microscopy (TEM) image of PBS/ EPO/HDA-MMT. of intercalation and the presence of some exfoliated zones of the PBS/EPO/HDA-MMT.

\section{Conclusions}

PBS/EPO-clay nanocomposites were modified on GCE (PBS/EPO/HDA-MMT-GCE). The nanocomposites had an extended potential working region, which was observed under different $\mathrm{pH}$ regions. The sensitivity under conditions of cyclic voltammetry was significantly dependent on the concentration, the $\mathrm{pH}$, the electrolyte and the scan rate. Stability of the PBS/EPO/HDA-MMT film coated on the GCE surface was also evident when examined at 10-time voltammogram. Behavioral electrochemical studies of the PBS/EPO/HDA-MMT compound were carried out on each of the contrast media by using TEM. The electrochemical properties of the compound in terms of redox current peaks of PBS/EPO/HDA-MMT were presented. It was found that $\mathrm{PBS} / \mathrm{EPO} / \mathrm{HDA}-\mathrm{MMT}$ was a suitable chemical compound as an antioxidant reagent without any side effects.

\section{Conflict of Interests}

The authors declare that no competing interest exists.

\section{References}

[1] M.M. Radhi, W.T. Tan, and M.Z. Rahman, Electrochemical characterization of the redox couple of $\left.[\mathrm{Fe}(\mathrm{CN}) 6]^{-3} \mathrm{Fe}(\mathrm{CN}) 6\right]^{-4}$ mediated by a grafted polymer modified glassy carbon electrode. Journal of Chemical Engineering of Japan, 2010, 43: 927-931.

[2] D.E. Labaye, C. Jerome, V.M. Gueskin, et al., Full electrochemical synthesis of conducting polymer films chemically grafted to conducting surfaces. J. Am. Chem. Soc., 2002, 18: 5222-5230.

[3] M.L. Peter, G.H. Rob, and M.A. Hempenius, Electrochemistry of surface-grafted stimulus-responsive monolayers of poly(ferrocenyldimethylsilane) on gold. Langmuir, 2005, 21: 5115-5123.

[4] C.J. Chuy, E. Ding, S. Swanson, et al., Conductivity and electrochemical ORR mass transport properties of solid polymer electrolytes containing poly(styrene sulfonic acid) graft chains. J. Electrochem. Soc., 2003, 150: 271279.

[5] M.M. Radhi, W.T. Tan, and A.J. Haider, Electrochemical characterization of the redox couple of $\mathrm{Fe}(\mathrm{II}) / \mathrm{Fe}$ (III) mediated by a grafted polymer electrode in nonaqueous electrolyte. Int. J. Electrochem. Sci., 2012, 7: 121-140.

[6] H. Xiong W. Zi-Dong, and D. Xie, Stable polymer electrolytes based on polyether-grafted $\mathrm{ZnO}$ nanoparticles for all-solid-state lithium batteries. J. Mater. Chem., 2006, 16: $1345-1349$.

[7] A. Oishi, M. Zhang, K. Nakayama, et al., Synthesis of 
poly(butylene succinate) and poly(ethylene succinate) including diglycollate moiety. Polym. J., 2006, 38(7): 710-715.

[8] E.A.J. Al-Mulla, Preparation of polylactic acid/epoxidized palm oil/fatty nitrogen compounds modified clay nanocomposites by melt blending. Polym. Scie. Ser. A, 2001, 53(2): 149-157.

[9] M.M. Reddy, A.K. Mohanty, and M. Misra, Biodegradable blends from plasticized soy meal, polycaprolactone, and poly(butylene succinate). Mac. Mol. Mat. Eng., 2011, 297: 455-463.

[10] H.S. Cho, H.S. Moon, and M. Kim, Biodegradability and biodegradation rate of poly(caprolactone)-starch blend and poly(butylene succinate) biodegradable polymer under aerobic and anaerobic environment. Was. Manag., 2010, 31: 475-480.

[11] S. Sugihara, K. Toshima, and S. Matsumura, New strategy for enzymatic synthesis of high-molecular-weight poly(butylene succinate) via cyclic oligomers. Mac. Molec. Rap.Comm., 2006, 7: 203-207.

[12] L.L. Yu, J. Cheng, and W.L. Qu, Mechanical properties of poly(butylene succinate) (PBS) biocomposites reinforced with surface modified jute fibre. Composites Part A: Appl. Sci. and Manuf., 2009, 40: 669-674.

[13] E.A.J. Al-Mulla, W.M.Z.W. Yunus, and N.A.B. Ibrahim, Epoxidized palm oil plasticized polylactic acid/fatty nitrogen compound modified clay nanocomposites: Preparation and characterization. Polym. Polym. Compo., 2010, 18: 451-459.

[14] K. Dean, L. Yu, S. Bateman, et al., Gelatinized starch/ biodegradable polyester blends: Processing, morphology, and properties. J. of App. Polym. Scie., 2007, 103(2): 802811.

[15] E.A.J. Al-Mulla, W.M.Z.W. Yunus, and N.A.B. Ibrahim, Properties of epoxidized palm oil plasticized polylactic acid, J. Mat. Sci., 2010, 45: 1942-1946.

[16] E.A.J. Al-Mulla, Preparation of new polymer nanocomposites based on poly (lactic acid)/fatty nitrogen compounds modified clay by a solution casting process. Fib. and Polym., 2011, 12(4): 444-450.

[17] E.A.J. Al-Mulla, Polylactic acid/epoxidized palm oil/ fatty nitrogen compounds modified clay nanocomposites: preparation and characterization. Kor. J. of Chem. Eng., 2011, 28(2): 620-626.

[18] M.M. Radhi, E.A.J. Al-Mulla, Use of a grafted polymer electrode to study mercury ions by cyclic voltammetry. Res. on Chem. Interm., 2015, 41: 1413-1420.
[19] F.A. Shemmari, A.A.A. Rabah, Comparative study of different surfactants for natural rubber clay nanocomposite preparation. Rendiconti Lincei, 2014, 25: 409-413.

[20] J.W. Park, S.S. Im, Phase behavior and morphology in blends of poly(L-lactic acid) and poly(butylene succinate). J. Appl. Polym. Sci., 2002, 86: 647-655.

[21] T. Yokohara, M. Yamaguchi, Structure and properties for biomassbased polyester blends of PLA and PBS. Eur. Polym. J., 2008, 44:677-685.

[22] D.J. Kim, W.S. Kim, and D.H. Lee, Modification of poly(butylene succinate) with peroxide: crosslinking, physical and thermal properties, and biodegradation. $J$. Appl. Polym. Sci., 2001, 81: 1115-1124.

[23] E.A.J. Al-Mulla, Lipase-catalyzed synthesis of fatty thioic acids from palm oil. J. Ole. Sci., 2011, 60(1): 41-45.

[24] E.A. J. Al-Mulla, W. M.Z.W. Yunus, N.A.B. Ibrahim, et al., Di fatty acyl urea from corn oil: Synthesis and characterization. J. Oleo Sci., 2010, 59: 157-160.

[25] Z. Kulinski, E. Piorkowska, Crystallization, structure and properties of plasticized poly(1-lactide). Polym., 2005, 46: 10290-10300.

[26] Z. Ren, L. Dong, and Y. Yang, Dynamic mechanical and thermal properties of plasticized poly(lactic acid). J. Appl. Polym. Sci., 2006, 101: 1583-1590.

[27] E.P. Giannelis, Polymer-layered silicate nanocomposites: synthesis, propertiesand applications. Appl. Organomet. Chem., 1998, 12: 675-680.

[28] B. Zidelkheir, M. Abdelgoad, Effect of surfactant agent upon the structure of montmorillonite. J. Therm. Anal. Calorim., 2008, 94: 181-187.

[29] E.P. Giannelis, R. Krishnamoorti, and E. Manias, Polymer-silicate nanocomposites model systems for confined polymers and polymer brushes. Adv. Polym. Sci., 1999, 138: 107-143.

[30] E.A.J. Al-Mulla, A.H. Suhail, and A.A. Saadon, New biopolymer nanocomposites based on epoxidized soybean oil plasticized poly(lactic acid)/fatty nitrogen compounds modified clay: Preparation andcharacterization. Ind. Crops Prod., 2011, 33: 23-29.

Copyright $(\subset$ Manar Ghyath Abd-Almutalib Al-Mosawy, Emad Abbas Jaffar Al-Mulla, and Muhammed Mizher Radhi. This is an open-access article distributed under the terms of the Creative Commons Attribution License, which permits unrestricted use, distribution, and reproduction in any medium, provided the original author and source are credited. 